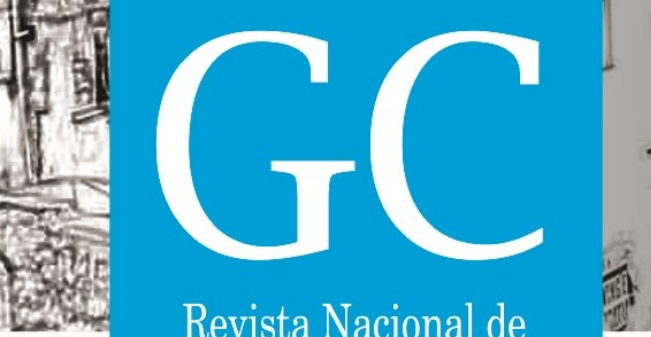

\title{
Avaliação da coleta seletiva no Plano Municipal de Gestão Integrada de Resíduos Sólidos de Barreiras - BA.
}

Evaluation of selective collection in Municipal Plan of Integrated Solid Waste

Management of Barreiras - BA.

Evaluación de la recolección selectiva en el Plan Municipal de Gestión Integrada de Resíduos Sólidos de Barreiras -BA.

Pollyana Ferreira da Silva Mestranda do Programa de Pós-graduação em Engenharia Urbana, UFScar, Brasil pollyferreiras@hotmail.com

Bernardo Arantes do Nascimento Teixeira Professor doutor do Programa de Pós-graduação em Engenharia Urbana, UFScar, Brasil. bernardo@ufscar.br 


\section{INTRODUÇÃO}

Os Resíduos Sólidos Urbanos (RSU) são heterogêneos (inertes, minerais e orgânicos) resultados das atividades humanas e da natureza. Contudo, gerenciar esses resíduos tem sido uma dificuldade no país por muitos anos, por isso, ainda temos muitas formas inadequadas de tratar e destinar o que se produz, como por exemplo, os lixões e vazadouros a céu aberto. Nestes casos, os resíduos podem gerar problemas sanitários, econômicos e ambientais (BRASIL, 2007).

Contudo, para sanar o problema mencionado, muitas soluções e tecnologias estão sendo desenvolvidas e difundidas, uma das soluções mais abordadas é a implantação da coleta seletiva para inserção dos materiais recicláveis nas cadeias produtivas. Neste sentido, o Instituto de Pesquisa Econômica Aplicada - IPEA (2010) verificou que existe uma possibilidade de expansão do mercado da reciclagem para a geração de renda estimada em R\$ 8 bilhões por ano no país, no contexto de universalização da reciclagem de materiais.

Desta forma, a Política Nacional de Resíduos Sólidos - PNRS, Lei $n^{\circ} 12$ 305, traz a coleta seletiva como um instrumento que possibilitará a reciclagem de materiais, e para consolidá-lo, a legislação prioriza a distribuição dos recursos da União aos municípios que optarem em seus Planos Municipais de Gerenciamento Integrado de Resíduos Sólidos - PMGIRS, a coleta seletiva com a participação de cooperativas. Assim, a política incentiva que a coleta seletiva e a participação de catadores de materiais recicláveis sejam premissa básica da construção dos modelos de gestão municipais.

Em relação ao município de Barreiras, a maior cidade do oeste da Bahia, com uma população segundo o Instituto Brasileiro de Geografia e Estatística (IBGE, 2015) estimada em 153.918 habitantes, a cidade é classificada como uma cidade média por Guedes et. al (2010) por ter influência econômica e cultural além de seus limites municipais. Desta forma, Barreiras corrobora com a formação de uma cadeia regional de negócios, serviços, educação e troca de informações.

Contudo, mesmo que o município se apresente em um contexto de amplo desenvolvimento de suas bases econômicas, a carência por infraestrutura compromete a qualidade de vida e a consolidação da sustentabilidade municipal, pois a cidade necessita de ampliação e implantação de serviços e equipamentos urbanos como: esgotamento sanitário, drenagem de águas pluviais e gestão de resíduos sólidos.

Segundo o Plano Municipal de Gestão Integrada de Resíduos Sólidos - PMGIRS/2014 do município a estimativa de geração de resíduos sólidos urbanos é de 124,8 ton./dia e uma geração per capita de $0,82 \mathrm{~kg} / \mathrm{hab}$./dia. Contudo, todos esses resíduos gerados ainda são dispostos em um lixão, por isso, o PMGIRS/2014 propõe que seja implantada a coleta seletiva e um aterro sanitário para receber os rejeitos do gerenciamento dos resíduos. Porém, nenhumas destas ações foram iniciadas mesmo já se passando mais de um ano da aprovação do plano. 
Desta forma, o estudo proposto tem resguardo no momento atual em que vive o município de Barreiras, ou seja, no binômio "necessidade x possibilidade", que coincide com o início da implantação do Plano Municipal de Gestão Integrada de Resíduos - PMGIRS/2014.

\section{OBJETIVO}

O presente trabalho tem por objetivo avaliar o Plano Municipal de Gestão Integrada de Resíduos Sólidos - PMGIRS/2014 de Barreiras - BA quanto aos aspectos relacionados à coleta seletiva.

\section{METODOLOGIA}

\section{1 ÁREA DE ESTUDO}

A área de estudo compreende município de Barreiras - BA em seu perímetro urbano, localizado na região oeste Bahia (figura 1). Segundo o Instituto de Geografia e Estatística IBGE (2015), o município tem uma população estimada de 153.918 habitantes, área de $7.538,152 \mathrm{~km}^{2}$ e uma densidade demográfica de $17,49 \mathrm{hab} . / \mathrm{Km}^{2}$ (figura 1 ).

Figura 1: Mapa de localização de Barreiras - BA.
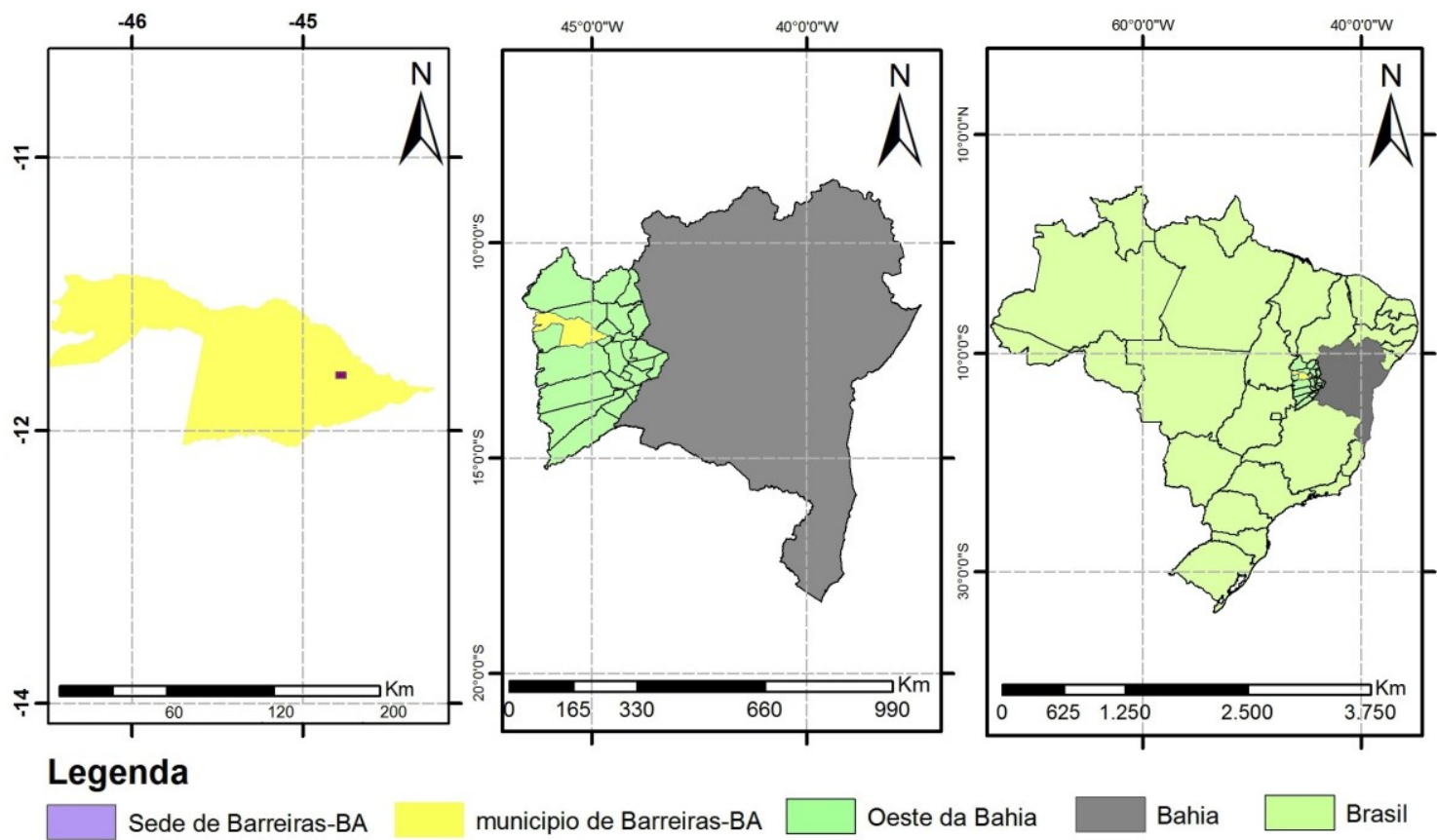

Sede de Barreiras-BA municipio de Barreiras-BA Oeste da Bahia Brasil

Fonte: Organizado pelo autor, 2015. 


\subsection{MÉTODO DE ANÁLISE}

A estratégia de investigação da pesquisa baseou-se numa concepção pós-positivista, em que as causas influenciam diretamente nos resultados. Por isso, a necessidade de se analisar o plano de gestão de resíduos dando ênfase aos aspectos relacionados à coleta seletiva. Quanto aos procedimentos, destaca-se a utilização do método qualitativo, realizando uma análise abrangente do objeto pesquisado.

Os procedimentos que foram realizados para alcançar o objetivo proposto consistem nas seguintes etapas (figura 2):

- Etapa 1: Descrição do gerenciamento de resíduos existente.

- Etapa 2: Avaliação do PMGIRS/2014 quanto aos aspectos relacionados a coleta seletiva.

- Etapa 3: Comparação do PMGIRS/2014 com a PNRS no contexto da coleta seletiva.

- Etapa 4: Avaliação Final.

Figura 2: Organograma da metodologia aplicada.

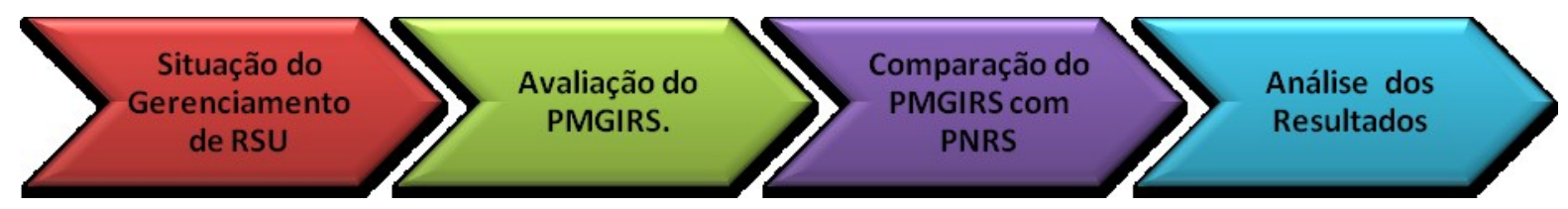

Fonte: Autores, 2016.

A primeira etapa foi realizada por meio da análise do PMGIRS/2014 e do reconhecimento de campo nas fases do gerenciamento, compreendendo a geração, a coleta, o acondicionamento, o transporte, o tratamento e a disposição final dos RSU.

$\mathrm{Na}$ avaliação do PMGIRS/2014 buscou-se pontuar como o plano concebe a coleta seletiva, a importância deste tema para o município, como foi abordado, o empenho financeiro previsto para esta área e a conexão com a PNRS.

A terceira etapa foi consequência da anterior, à medida que o PMGIRS/2014 está de acordo com o proposto pela PNRS.

$\mathrm{Na}$ fase de avaliação final compilaram-se os dados obtidos anteriormente para sanar as indagações que cercam o objetivo da pesquisa. 


\section{RESULTADOS}

\subsection{SITUAÇÃO DOS RSU EM BARREIRAS - BA}

O manejo dos resíduos sólidos no município é realizado principalmente pela Prefeitura Municipal, sendo que o serviço de limpeza urbana é concretizado por equipes do Departamento de Limpeza Urbana da Secretaria de Serviços Públicos e Transporte. Este serviço compreende: serviços de varrição; poda e capina; limpeza de feiras livres; serviços de desobstrução de sarjetas e bueiros; coleta de animais mortos de pequeno e grande porte. $\mathrm{E}$ segundo o PMGIRS/2014, coleta-se aproximadamente 10 toneladas de resíduos por dia, compostos principalmente por areia, atendendo em torno de $20 \%$ das vias urbanas (figura 3 da tabela 1).

O gerenciamento dos RSU (domiciliares e comerciais), compreendendo, a coleta, o transporte e a destinação final de resíduos domiciliares, é designado a uma empresa contratada pelo município. A coleta é realizada por sistema porta a porta, com caminhões compactadores e encaminhados para um lixão a 18 quilômetros do centro urbano as margens da BR-242 (sentido Salvador-BA). Assim, segundo uma estimativa feita pelo PMGIRS/2014, o município produz 124,8 ton./dia de RSU, consequentemente, $0,82 \mathrm{~kg} / \mathrm{hab} . / \mathrm{dia}$, dados que demonstram a necessidade de solucionar de forma emergencial principalmente a disposição final dos RSU, que estão causando impactos ambientais na área de disposição (figura 1 da tabela 1).

A coleta seletiva no município é realizada pela iniciativa de cooperativas de catadores que realizam este trabalho na área urbana e por catadores que prestam este serviço no lixão da cidade. Desta forma, o município não possui institucionalmente nenhum sistema de coleta seletiva que atenda todo seu território. Segundo o PMGIRS/2014, em levantamento feito pela Secretaria Municipal de Trabalho e Promoção Social, no município, em torno de 60 famílias sobrevivem da coleta de resíduos recicláveis, sendo que $80 \%$ destes núcleos familiares desenvolvem esta atividade no lixão da cidade (incluindo crianças, idosos e adultos) (figura 2 da tabela 1).

Assim, o gerenciamento dos resíduos no município, desempenhado de forma irregular, desencadeia diversos problemas de cunho ambiental, social e econômico, pois, segundo a PNRS ficou proibida a utilizações de lixões para a destinação final de resíduos, a presença de catadores e animais domésticos nestes ambientes. Além disso, tem-se que destacar a degradação ambiental que o descarte inadequado dos RSU está causando possivelmente ao solo, as águas subterrâneas e superficiais e ao ar. Ressalta-se também, os impactos sociais desta situação, em particular, aos catadores que trabalham e vivem em situação insalubre e sem condições dignas de trabalho e sobrevivência. Desta maneira, a coleta seletiva no município ainda é vista como uma atividade econômica realizada por munícipes excluídos socialmente e com poucas oportunidades de transformação social (figura 4 da tabela 1 ). 
implementação do PMGIRS e a aprovação do PMGIRS (BARREIRAS, 2014).

Cabe salientar, que a participação social no processo de elaboração do plano foi amplificada, pois a estratégia de realização de consultas públicas em setores da zona urbana e zona rural colocaram os espaços de discussão mais próximos da população, facilitando o diagnóstico e proposições para serem incluídas no PMGIRS/2014. Quanto à participação de agentes diretamente ligados à coleta seletiva, tem-se como registro, a participação de cooperativas de catadores, porém, não consta a participação das empresas revendedoras de materiais recicláveis (atravessadores) e dos catadores que trabalham no lixão da cidade, sendo que tinham muito a contribuir com sugestões que poderiam ser valiosas na concepção da proposta de coleta seletiva para o município.

Com base nos objetivos propostos pelo PMGIRS/2014, percebe-se uma ambiguidade em seu conteúdo, pois o objetivo geral é criar e implantar um sistema de gestão integrada de resíduos, visando à melhoria dos aspectos socioambientais e econômicos, propondo soluções para redução e destinação ambientalmente segura dos resíduos gerados no município. Porém, temse como um dos objetivos específicos, ampliar e apoiar significativamente a coleta seletiva, demonstrando a desconexão entre os objetivos. Pois, como que se irá ampliar a coleta seletiva se o município não tem se quer uma gestão integrada de RS e coleta seletiva institucionalizada pelo ente municipal. Assim como, não seria adequado afirmar que irá ser ampliado um serviço que a cidade atualmente não possui, sendo prestado por catadores em associações, cooperativas e catadores autônomos sem a parceria com o poder público municipal.

Em outros objetivos específicos, o PMGIRS/2014 coloca que se devem adotar ações sociais para apoiar catadores formalizados em cooperativas e associações, além disso, promover campanhas que incentivem e propiciem a organização de catadores informais. Contudo, não se tem como objetivo a prestação do serviço da coleta seletiva que deveria ser promovido pelo poder público municipal em parceria com cooperativas ou associações de catadores. Além disso, deve-se ressaltar que estas instituições devem ser autônomas, assim, autogeridas, não tendo como medir até que ponto essa interferência do poder público municipal em inserir catadores informais nestas organizações não feriria este princípio de gestão.

Em relação ao diagnóstico apresentado no PMGIRS/2014 feito em consultas públicas, atendose especificamente ao tema coleta seletiva, pode-se ressaltar que $27 \%$ dos participantes de uma das consultas na zona urbana, afirmaram não fazer a separação dos seus resíduos por falta de conhecimento e também por falta da coleta seletiva no município. Como solução a esta situação a consulta gerou a seguinte proposição: $47 \%$ sugeriu colocar contêineres e lixeiras individuais para coleta dos resíduos domiciliares, coleta seletiva e programas de compostagem em residências; $40 \%$ dos consultados sugeriram a criação de postos de trabalho na área da reciclagem e o incentivo pelo poder público às associações e cooperativas de reciclagem. Este cenário da consulta demonstra a intenção dos munícipes para se inserir num sistema de coleta seletiva que poderá ser criado pelo município (BARREIRAS, 2014).

Ainda sobre os resultados das consultas, com o tema, coleta seletiva: geração de emprego, 
associações de catadores de materiais recicláveis. Estas metas e propostas de ações revelam a inclinação que o município teve em atender as exigências da PNRS, assim como, refletiu sobre como seria a solução que melhor atendesse as necessidades e potencializasse os recursos que os materiais recicláveis representam para a cidade.

Em relação às metas e ações para fortalecer as cooperativas de catadores, o PMGIRS/2014 se propõe a incentivar a organização destas instituições e para tal, subsidiar os gastos para que a usina de triagem e os PEV's sejam mantidos pela prefeitura municipal. Além disso, prover uniformes, EPI's (Equipamentos de Proteção Individual) e apoio jurídico. Contudo, não se tem alocação de recurso nos custos estimados para a capacitação dos cooperados, mesmo este sendo um item previsto no orçamento realizado para os investimentos ao longo do tempo. Assim, ressalta-se a importância dessa decisão política de fazer com que a operação do sistema da reciclagem seja feito por cooperativas, mas tem-se que salientar que o investimento com a capacitação dos catadores é uma ação fundamental para o bom funcionamento do programa de reciclagem.

Quanto ao apoio jurídico as cooperativas ou as associações, tem-se que ter cautela, pois o PMGIRS/2014 coloca como prestador de serviço a procuradoria municipal. Desta forma, reflete-se novamente, sobre a autonomia e o sistema de autogestão que se enquadra instituições como as cooperativas, esta poderia ser uma forma de controle político, econômico e financeiro destas organizações. Nesta perspectiva, estas instituições deveriam ter sua própria contabilidade, assessoria jurídica e administração baseada em seus princípios de autogestão.

Um dos objetivos apresentados pelo PMGIRS/2014 a serem alcançados pelas metas e ações é a promoção da inclusão social dos catadores de materiais recicláveis. Porém a única ação que se observa no plano nesse sentido é incluir os cooperados apenas em programas como Minha Casa Minha Vida, Bolsa Família e outros programas da Secretaria Municipal de Trabalho e Promoção Social, não apresentando nenhum programa que realmente se enquadre a realidade do trabalhador da reciclagem, que inclua seu trabalho, função social, função ambiental e promova a profissão para que este cidadão se reconheça como parte fundamental para a gestão dos resíduos no município e realmente promova a transformação social.

O programa de coleta seletiva proposto pelo PMGIRS/2014 tem características de projeto piloto como o próprio plano menciona, mas se estabelece que seja executado em seis escolas municipais e na área central da cidade, a partir da solicitação voluntária dos moradores e comerciantes que se sensibilizarem em participar do programa. Assim, para a operacionalização do programa preveem-se dois PEV's, um centro de triagem, dois caminhões para a coleta porta-a-porta, recipientes para que a população separe na fonte os resíduos recicláveis, além da estrutura física e mobiliária necessária para o funcionamento do programa. Salienta-se que este programa será parte inicial para institucionalização da coleta seletiva no município.

O programa piloto nas seis escolas previstas pelo PMGIRS/2014 propõe que o tema da coleta 
seletiva seja inserido no contexto escolar a partir de oficinas, palestras e seminários que envolva toda a comunidade escolar e que os conhecimentos sejam aplicados na grade escolar dos alunos. Desta forma, entende-se que este é um importante projeto que pode trazer mudanças significativas na gestão dos resíduos sólidos na perspectiva de que a educação pode ser uma ferramenta de transformação social imutável.

\subsection{ADEQUAÇÃO DO PMGIRS/2014 À PNRS, NOS ASPECTOS RELACIONADOS À COLETA SELETIVA}

A PNRS preconiza que os municípios que optarem pela coleta seletiva com a participação de cooperativas ou outras formas de associação de catadores de materiais reutilizáveis e recicláveis, formadas por pessoas físicas de baixa renda, terão prioridade para acessar os recursos da União. Assim, como o PMGIRS/2014 utiliza como uma das soluções para a gestão dos RS no município, a coleta seletiva, poderá ter prioridade frente aos municípios brasileiros caso implante este instrumento da PNRS.

A PNRS também traz que os planos devem prever metas de redução, reutilização, coleta seletiva e reciclagem, entre outras, com vistas a reduzir a quantidade de rejeitos encaminhados para disposição final ambientalmente adequada. Contudo, o PMGIRS/2014 foi insuficiente neste sentido, pois não apresenta metas para redução da geração de RS, nenhuma solução ou metas para a reutilização de RS, apenas trabalha na perspectiva para a não geração a partir dos trabalhos da educação ambiental realizados com a população.

Em relação à responsabilidade compartilhada pelo ciclo de vida dos produtos, o PMGIRS/2014 tem metas para que, em um horizonte de vinte anos, sejam destinados de maneira ambientalmente adequada dos os resíduos passíveis de logística reversa. Para tanto, prevê-se a construção de PEV's com recursos públicos municipais, porém não fica explicito se é de responsabilidade do poder público ou dos agentes envolvidos na logística reversa (comerciantes, distribuidores, exportadores, fabricantes). Além disso, pretende-se fiscalizar os estabelecimentos passíveis da prestação deste serviço, incentivar os que estiverem cumprindo a política com abono fiscal ou selos verdes e estimular a população a separar os resíduos que devem ser encaminhados à logística reversa. Contudo, o PMGIRS/2014 não descreve as formas e os limites de participação do poder público local na coleta seletiva e na logística reversa.

\section{CONCLUSÃO}

O gerenciamento dos resíduos no município de Barreiras - BA ainda é um desafio para a gestão municipal, sociedade e organizações envolvidas nesta área da gestão pública, pois constata-se prontamente, impasses sociais, econômicos, ambientais e políticos que interferem diretamente na gestão dos RSU, como a vagarosidade do aparelho público municipal em iniciar as atividades previstas no plano, para que as demais ações intrínsecas aos inúmeros sujeitos 
da cadeia da coleta seletiva possam inseri-se neste ciclo do mercado social da reciclagem e de fato utilizar-se deste instrumento para a gestão dos resíduos sólidos urbanos.

Por consequência, o gerenciamento dos resíduos ainda é feito de maneira inadequada, principalmente em relação à disposição final, pois como já mencionado, a alimentação do lixão diariamente com RSU subsidia a sobrevivência de várias famílias na atividade insalubre da catação destes resíduos. Além disso, assumi-se o passivo ambiental gerado pela disposição direta dos RSU ao solo, estando sujeito às ações da degrabilidade dos materiais orgânicos e inorgânicos dispostos.

Propositivamente, o PMGIRS/2014 é um instrumento que norteará a política municipal para a gestão dos RSU, e para tal, o plano apresenta importantes metas e ações que deverão ser realizadas. Quanto à coleta seletiva, o plano prevê a parceria com cooperativas e associações de catadores para a realização da coleta no município como uma das soluções para o gerenciamento de resíduos. Assim, apresenta-se a intenção do município em entrar no contexto da reciclagem, porém, o documento apresenta algumas fragilidades em relação à priorização das políticas públicas voltadas para fomentar a parceria com os catadores de materiais recicláveis e no entendimento do conceito de cooperativismo. Contudo, estas dificuldades poderão ser superadas na implementação das propostas do plano, desde que sejam revisitadas as prioridades da gestão pública municipal para a concretização dos objetivos elucidados pelo PMGIRS/2014.

Quanto às exigências feitas pela PNRS no âmbito da coleta seletiva, o PMGIRS/2014 é oportunamente adequado, porém, não determina as metas de redução da geração de resíduos, fato importante na hierarquização do gerenciamento dos RSU e não conseguiu determinar as formas e os limites de participação do poder público local na coleta seletiva e na logística reversa. Desta forma, estas limitações do plano podem conferir vulnerabilidade à gestão dos RSU no momento da implantação do plano, por isso, é necessária a revisão e definição das lacunas apresentadas pelo PMGIRS/2014.

\section{AGRADECIMENTO}

Os autores agradecem a CAPES (Coordenação de Aperfeiçoamento de Pessoal de Nível Superior) por fomentar este trabalho realizado no Programa de Pós-graduação em Engenharia Urbana da Universidade Federal de São Carlos.

\section{REFERÊNCIAS BIBLIOGRÁFICAS}

BARREIRAS. Decreto no 778/2013. Cria o Comitê Diretor e o Grupo de Sustentação e dispõe sobre o processo de elaboração do Plano Municipal de Gerenciamento Integrado de Resíduos Sólidos do Município de Barreiras. Disponível em: < http://www.barreiras.ba.gov.br/diario/pdf/diario1649.pdf>. Acesso em: 20 de abril de 2016. 
BARREIRAS. Plano de Gestão Integrada de Resíduos Sólidos de Barreiras - Bahia. Barreiras BA, 2014. Disponível em: < http://barreiras.ba.gov.br/wpcontent/uploads/2014/12/Versao_PMGIRS_27_11_14.pdf>. Acesso em: 20 de abril de 2016.

BRASIL. Fundação Nacional de Saúde. Manual de Saneamento. 3. ed. rev. - Brasília: Fundação Nacional de Saúde, 2007.

BRASIL. Lei no 12.305, de 02 de agosto de 2010. Institui a Política Nacional de Resíduos Sólidos; altera a Lei no 9.605, de 12 de fevereiro de 1998; e dá outras providências. Disponível em: < http://www.planalto.gov.br/ccivil_03/_ato2007-2010/2010/lei/l12305.htm>. Acesso em 12 de abril de 2016.

GUEDES, J. F. de C. e PORTELLA, R. B. Cidade média e centralidade: o exemplo de BarreirasBA. In: I Simpósio Regional de Geografia do Cerrado - SIREGEO 09 a 12 de Outubro de 2010 Barreiras - BA.

IBGE. Instituto Brasileiro de Geografia e Estatística. Dados gerais do município de Barreiras BA. $\quad 2015.2$ Disponível em: $<$ http://www.cidades.ibge.gov.br/xtras/perfil.php?lang=\&codmun=290320\&search=bahia | bar reiras >. Acesso em: 02 de maio de 2016.

IPEA - Instituto de Pesquisa Econômica Aplicada. Pesquisa sobre pagamento por serviços ambientais urbanos para gestão de resíduos sólidos. Brasília: IPEA, 2010. Disponível em: <http://goo.gl/tTVr>. Acesso em: 02 de maio de 2016.

JORNAL GAZETA DO OESTE, Prefeitura de Barreiras divulga cronograma de coleta de lixo. Barreiras, 2013. Disponível em: $<$ http://jornalgazetadooeste.com.br/noticiasdiversas/prefeitura-de-barreiras-divulga-cronograma-de-coleta-de-lixo/>. Acesso em: 20 de agosto de 2016. 